\title{
Cannabinoids in Neurodegenerative Disorders and Stroke/Brain Trauma: From Preclinical Models to Clinical Applications
}

\author{
Javier Fernández-Ruiz ${ }^{1,2,3}$ • María A. Moro ${ }^{4,5}$ • José Martínez-Orgado ${ }^{6}$
}

Published online: 11 August 2015

(C) The American Society for Experimental NeuroTherapeutics, Inc. 2015

\begin{abstract}
Cannabinoids form a singular family of plantderived compounds (phytocannabinoids), endogenous signaling lipids (endocannabinoids), and synthetic derivatives with multiple biological effects and therapeutic applications in the central and peripheral nervous systems. One of these properties is the regulation of neuronal homeostasis and survival, which is the result of the combination of a myriad of effects addressed to preserve, rescue, repair, and/or replace neurons, and also glial cells against multiple insults that may potentially damage these cells. These effects are facilitated by the location of specific targets for the action of these compounds (e.g., cannabinoid type 1 and 2 receptors, endocannabinoid inactivating enzymes, and nonendocannabinoid targets) in key cellular substrates (e.g., neurons, glial cells, and neural progenitor cells). This potential is promising for acute and
\end{abstract}

Javier Fernández-Ruiz

jjfr@med.ucm.es

1 Departamento de Bioquímica y Biología Molecular, Facultad de Medicina, Instituto Universitario de Investigación en Neuroquímica, Universidad Complutense, Madrid, Spain

2 Centro de Investigación Biomédica en Red sobre Enfermedades Neurodegenerativas (CIBERNED), Madrid, Spain

3 Instituto Ramón y Cajal de Investigación Sanitaria (IRYCIS), Madrid, Spain

4 Departamento de Farmacología, Facultad de Medicina, Instituto Universitario de Investigación en Neuroquímica, Universidad Complutense, 28040 Madrid, Spain

5 Instituto de Investigación Hospital 12 de Octubre (i+12), Madrid, Spain

6 Servicio de Neonatología, Hospital Clínico San Carlos, Madrid, Spain chronic neurodegenerative pathological conditions. In this review, we will collect all experimental evidence, mainly obtained at the preclinical level, supporting that different cannabinoid compounds may be neuroprotective in adult and neonatal ischemia, brain trauma, Alzheimer's disease, Parkinson's disease, Huntington's chorea, and amyotrophic lateral sclerosis. This increasing experimental evidence demands a prompt clinical validation of cannabinoid-based medicines for the treatment of all these disorders, which, at present, lack efficacious treatments for delaying/arresting disease progression, despite the fact that the few clinical trials conducted so far with these medicines have failed to demonstrate beneficial effects.

Keywords Cannabinoids · Endocannabinoid signaling system $\cdot \mathrm{CB}_{1}$ and $\mathrm{CB}_{2}$ receptors $\cdot \mathrm{FAAH}$ and MAGL enzymes $\cdot$ Neurodegenerative disorders $\cdot$ Neuroprotection

\section{Overview on the Neuroprotective Properties of Cannabinoids}

The neuroprotective potential of compounds targeting the endocannabinoid system (e.g., cannabinoid agonists, inhibitors of endocannabinoid inactivation, and allosteric modulators) has been extensively investigated over the last 15 years [1]. This potential is based on the ability of these compounds to limit the influence of multiple cytotoxic stimuli (e.g., excitotoxicity, oxidative stress, inflammation, etc.) on neuronal homeostasis and survival. It is now obvious that these stimuli collaborate for deteriorating neurons in most of neurodegenerative disorders, so a reliable strategy to preserve neurons from death needs the combination of protective effects on all or on most of these cytotoxic 
stimuli, this representing the major added-value of cannabinoids when compared with other types of compounds also investigated for their neuroprotective properties [e.g., antioxidants, $N$-methyl-D-aspartate (NMDA) and $\alpha$ amino-3-hydroxy-5-methyl-4-isoxazolepropionic acid antagonists, calcium channel blockers, inhibitors of apoptosis, and anti-inflammatory agents] [1]. The advantage of cannabinoids in neuroprotection is their broad-spectrum profile determined by their activity at multiple molecular sites not only within the endocannabinoid system, but also outside this neuromodulatory system, and the location of those potential targets for cannabinoids in all key cellular elements in relation to the control of neuronal survival (e.g., neurons, astrocytes, resting and reactive microglia, oligodendrocytes and oligodendrocyte precursor cells, and neural progenitor cells) and also in key brain structures [e.g., blood-brain barrier (BBB)] [1]. This multiplicity of molecular sites allows for a unique cannabinoid (or a combination of cannabinoids with different profiles) to possibly reduce excitotoxicity by acting through neuronal cannabinoid type 1 receptors $\left(\mathrm{CB}_{1} \mathrm{R}\right)$, as well as the toxic influence of reactive microgliosis by acting through microglial cannabinoid type 2 receptors $\left(\mathrm{CB}_{2} \mathrm{R}\right)$, or enhancing the trophic and metabolic support to neurons by acting through astroglial $\mathrm{CB}_{1} \mathrm{R}$ or $\mathrm{CB}_{2} \mathrm{R}$. These effects may also include actions through mechanisms that do not involve cannabinoid receptors/enzymes but interactions with transcription factors [e.g., nuclear factor (erythroidderived)-like 2 (Nrf-2), nuclear factor kappa B (NFkB)] or nuclear receptors of the peroxisome proliferatoractivated receptor (PPAR) family to limit oxidative stress/ inflammatory responses, with elements of other transmission systems (e.g., 5- $\mathrm{HT}_{1 \mathrm{~A}}$ receptors) for the control of blood supply, or with components of the adenosine signaling pathway $[1,2]$ (see Fig. 1 for an overview of all molecular and cellular mechanisms proposed for the neuroprotective properties of cannabinoids).

The objective of this review is to collect the preclinical evidence generated in the last 15 years, which support the need to develop cannabinoid-based therapies for the treatment of disease progression in experimental models of acute (e.g., adult and neonatal ischemia, brain trauma) or chronic (Alzheimer's disease [AD], Parkinson's disease [PD], Huntington's disease [HD] and amyotrophic lateral sclerosis (ALS)] neurodegenerative disorders. In all cases, we will also review the changes observed in specific endocannabinoid elements of this signaling system during the progression of each pathology and will discuss how they can be relevant to pharmacology, for example they may indicate the most interesting and promising pharmacological targets for the development of specific neuroprotective therapies (see Fig. 2 for an overview on investigated targets for these disorders). We will end each section with a review of the clinical evidence (if it exists),

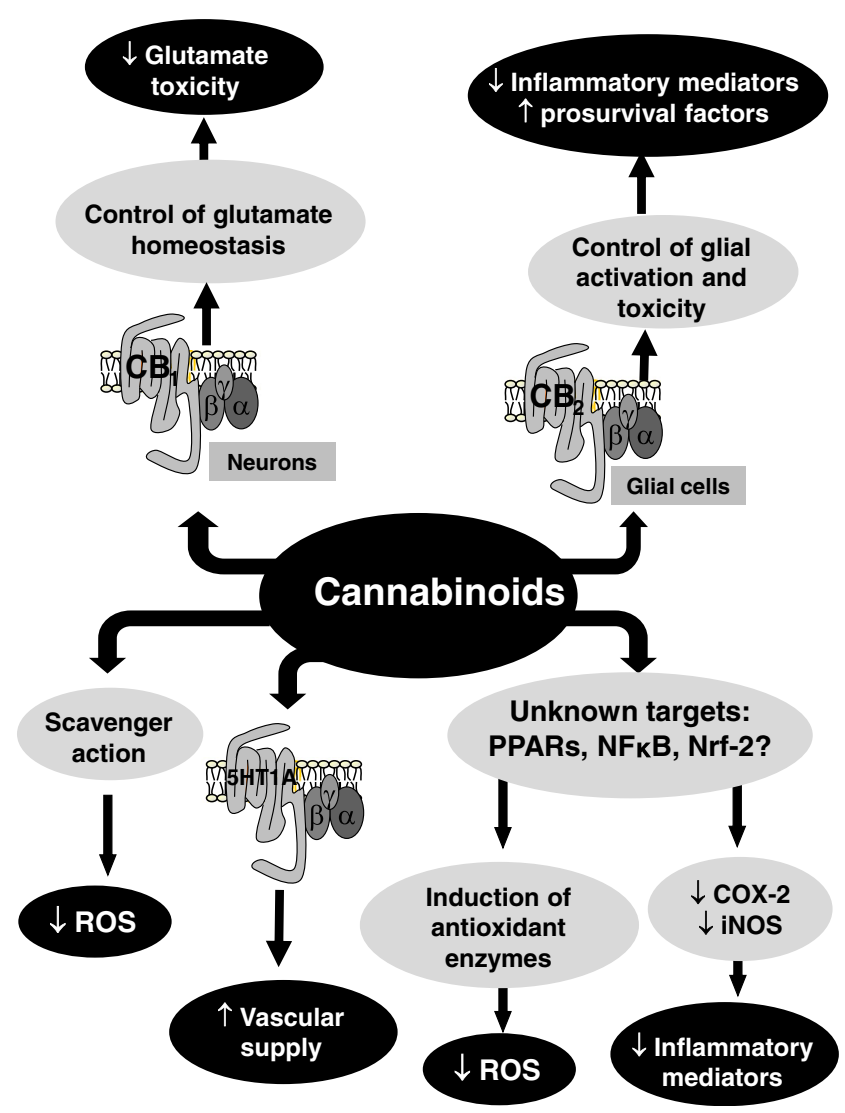

Fig. 1 Overview of the molecular and cellular mechanisms enabling the neuroprotective properties of cannabinoids. $\mathrm{CB}_{1}=$ cannabinoid type 1 receptor; $\mathrm{CB}_{2}=$ cannabinoid type 2 receptor; $\mathrm{PPAR}=$ peroxisome proliferator-activated receptor; $\mathrm{NFkB}=$ nuclear factor kappa $\mathrm{B}$; Nrf-2= nuclear factor (erythroid-derived)-like $2 ; \mathrm{ROS}=$ reactive oxygen species; COX-2 $=$ cyclooxygenase 2 ; iNOS $=$ inducible nitric oxide synthase

reasons for their potential failures and proposals for a better development of these therapies in patients.

\section{Cannabinoids and Acute Brain Damage: Stroke and Brain Trauma}

Stroke remains the second most common cause of death and the third most common cause of disability worldwide. Approximately $80 \%$ of strokes are attributable to the occlusion of a blood vessel (ischemic stroke), whilst the rest is mainly associated with vessel rupture (hemorrhagic stroke) [3]. When a blood vessel that irrigates the brain tissue is occluded, ischemic brain damage is triggered by excessive release of the excitatory neurotransmitter glutamate as a result of energy failure and ion gradient collapse, resulting in a reversal of glutamate uptake via glutamate transporters. Excessive glutamate-evoked $\mathrm{Ca}^{2+}$ entry via NMDA receptors further promotes cell death by triggering an excitotoxic cascade that involves the activation of $\mathrm{Ca}^{2+}$-dependent enzymes, the disruption of mitochondrial function, and cell necrosis or 
Fig. 2 Summary of the targets and types of cannabinoid-based therapies that are being investigated in the different neurodegenerative conditions included in this review. FAAH = fatty acid amide hydrolase; MAGL $=$ monoacylglycerol lipase; $\mathrm{CB}_{1}=$ cannabinoid type 1 receptor; $\mathrm{CB}_{2}=$ cannabinoid type 2 receptor; PPAR $=$ peroxisome proliferator-activated (erythroid-derived)-like 2; NFkB $=$ nuclear factor kappa $\mathrm{B} ; \mathrm{CBD}=$ cannabidiol receptor; Nrf-2 = nuclear factor

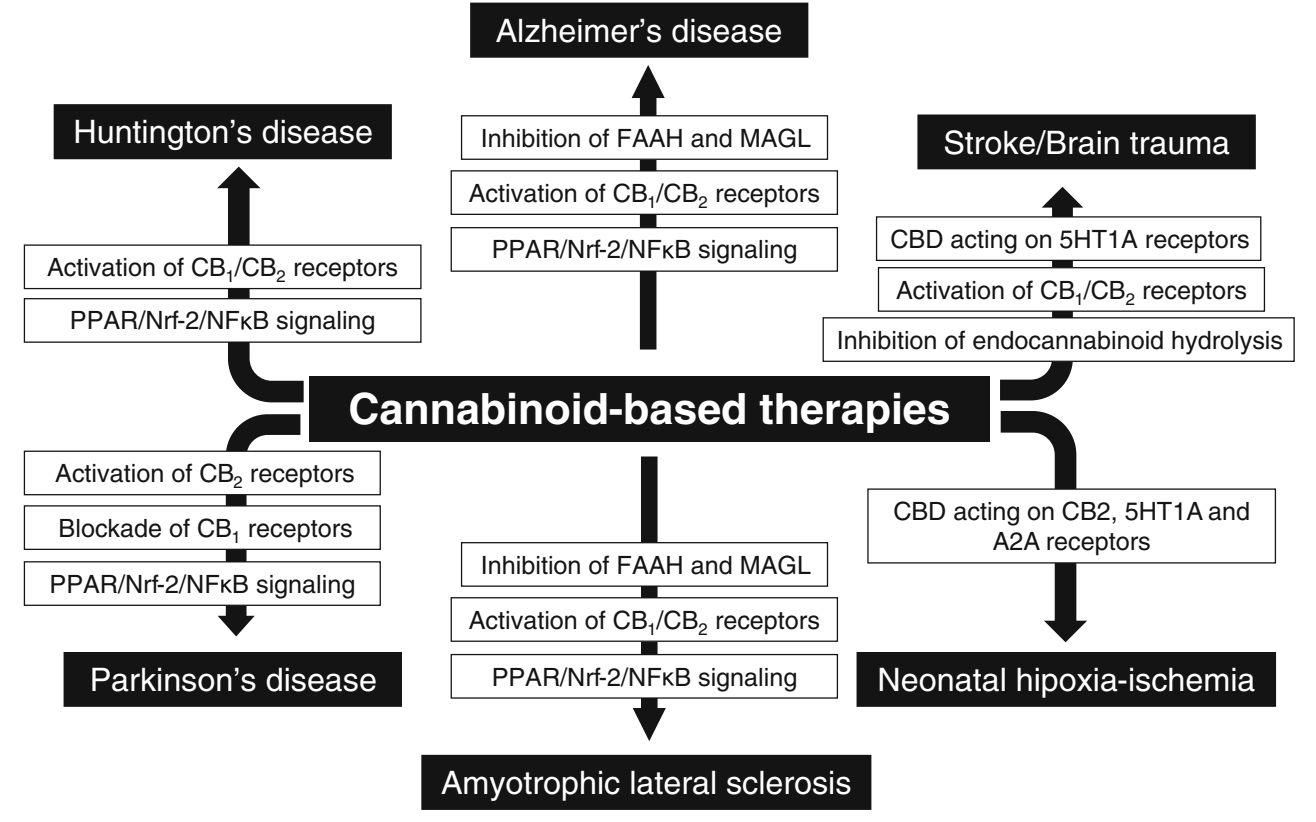

Alzheimer's disease

apoptosis. Ischemic brain injury is exacerbated by a robust inflammatory response that involves a local reaction, as well as an influx of blood-borne cells with production of inflammatory mediators, including cytokines, chemokines, proteases, reactive oxygen species, and vascular adhesion molecules (reviewed in [4]). For the acute phase of ischemic stroke, the only pharmacological treatment is the recanalization of the occluded vessel with thrombolytic therapy with tissue plasminogen activator. However, owing to its narrow time window, $<5 \%$ of stroke patients receive this treatment. Although the use of mechanic thrombectomy is helping to expand this window, it is still imperative to pursue the search of new therapeutic targets amenable to pharmacological manipulation for stroke patients [5]. Traumatic brain injury (TBI) is another important focal form of acquired brain injury that occurs when a sudden trauma damages the brain. It is usually caused either by closed or by open, penetrating head injury, and is often the result of car accidents, firearms or falls [6]. Since its pathophysiology shares many of its mechanisms with stroke, we will address these 2 pathologies together. Both pathological conditions should be completed with the study of spinal injury, but owing to space constraints, we will not address the effects of cannabinoids in spinal injury here.

Cannabinoids have been proposed as promising neuroprotective agents for the treatment of stroke and TBI [7]. This possibility has been predominantly investigated in experimental models of both disorders in laboratory animals, although some of the studies supporting this promise have been conducted with the cannabinoid administered before the cytotoxic insults, a fact that is not possible to reproduce in the case of humans, so the results of these specific studies should be taken with the necessary caution. For stroke, most common models are those caused by middle cerebral artery occlusion (MCAO) in rats or mice, either permanent (pMCAO) or followed by reperfusion [transient $\mathrm{MCAO}(\mathrm{tMCAO})$ ], as well as in vitro models of oxygen/glucose deprivation. In the case of TBI, damage is most commonly caused either by closed (concussion) or open head injury (stab wound). The cannabinoids having beneficial effects in these models included 1) dexanabinol (HU-211) [8-11], which is a synthetic compound having a chemical structure of a classic cannabinoid but no activity at cannabinoid receptors; 2) nonselective synthetic cannabinoid agonists such as HU-210, the active enantiomer of HU-211 [12], WIN 55,212-2 [13, 14], TAK-937 [15, 16], and BAY 38-7271 $[17,18] ; 3)$ phytocannabinoids such as $\Delta^{9}$ tetrahydrocannabinol $\left(\Delta^{9}\right.$-THC) [19], which binds not only $\mathrm{CB}_{1} \mathrm{R}$ and $\mathrm{CB}_{2} \mathrm{R}$, but also cannabidiol (CBD), which has no affinity at these receptors but was highly active against brain ischemia [20-22]; 4) endocannabinoids such as 2arachidonoylglycerol (2-AG), in particular in TBI induced by closed head injury [23-25], but also in experimental ischemia [26], and also anandamide [27] and its related signaling lipids palmitoylethanolamide (PEA) [28], oleoylethanolamide [27], and $N$-arachidonoyl-L-serine (AraS) [29]; and 5) selective $\mathrm{CB}_{2} \mathrm{R}$ targeting ligands such as $\mathrm{O}-3853$, O-1966, and JWH-133 [30-35]. Most of these studies were conducted with the cannabinoid administered at least after the cytotoxic insult [12-19, 21-26, 28-35]. In most cases, the benefits obtained with these cannabinoid-related compounds (e.g., improved neurological performance, reduced infarct size, edema, BBB disruption, inflammation and gliosis, and control of immunomodulatory responses) involved the activation of $\mathrm{CB}_{1} \mathrm{R}$ (e.g., HU-210 [12], WIN55,212-2 [13, 14], TAK-937 [15, 16], BAY 38-7271 [17, 18], $\Delta^{9}$-THC [19], and PEA [36]) and/or $\mathrm{CB}_{2} \mathrm{R}$ (e.g., AraS [29], O-3853, O-1966, and JWH-133 [30-35]) . Similar findings derive from experiments using 
mice with a genetic deficiency in $\mathrm{CB}_{1} \mathrm{R}$ or, to a lesser extent, $\mathrm{CB}_{2} \mathrm{R}$. For example, $\mathrm{CB}_{1}^{-/-}$mice showed increased infarct size and neurological deficits after tMCAO, concomitant with a reduction in cerebral blood flow and NMDA excitotoxicity [37], and a similar greater vulnerability was also found in TBI models [24], then supporting the protective role of $\mathrm{CB}_{1} \mathrm{R}$ against both pathological conditions. In the case of $\mathrm{CB}_{2}{ }^{-/}$ mice, results were controversial, with a study reporting larger cerebral infarction and a worsened neurological function after tMCAO [30], but others describing no differences using permanent MCAO [32, 33], despite the notable effects found in pharmacological experiments with compounds selectively activating the $\mathrm{CB}_{2} \mathrm{R}$ [30-35]. These types of agonists are particularly interesting for a possible therapeutic application in stroke and TBI because of the lack of psychoactivity of their selective agonists. In addition, their strong anti-inflammatory profile appears to be one of the most consistent mechanisms leading to reduction of the lesion, by actions affecting resident, vascular, and peripheral cells. It is also important to remark that the benefits of certain cannabinoids in acute stroke and TBI also involve effects on other pharmacological targets, such as the blockade of NMDA receptors (e.g., HU-211 [8-11]), the activation of 5-HT $1 \mathrm{~A}$ receptors (e.g., CBD [20-22]), and the activation of transient receptor potential vanilloid-type 1 receptors (e.g., PEA [36] and AraS) [29]). It is also possible that part of these beneficial effects may be related to the hypothermic effects of cannabinoids, but it is well known that such effects are $\mathrm{CB}_{1} \mathrm{R}$-mediated $[12,38,39]$. Lastly and apart from the acute phase, both stroke and TBI have in common a chronic phase characterized by severe functional sequelae. This late phase offers, at least theoretically, a broader window for promoting repair and decreasing disability, in which there might be some room for cannabinoids based on their capability to induce proliferation of neural progenitors cells $[40,41]$, their differentiation and migration at lesioned sites (Moro et al., unpublished results), or the differentiation of oligodendrocyte precursor cells to produce remyelination [42] —all these possibilities have already been investigated in experimental brain ischemia.

The neuroprotective and neurorepair effects of cannabinoids in stroke and TBI may be facilitated by the responses experienced by endocannabinoids and their receptors and enzymes during the progression of both pathological conditions. This may be the case, for example, of the transient accumulation of 2-AG at the site of injury in experimental TBI [23]. By contrast, in the neonatal rat brain, the exposure to concussive head trauma induced a moderate increase in the levels of anandamide and other $\mathrm{N}$-acylethanolamines, but not of 2AG and other 2-monoacylglycerols [43, 44]. Further studies demonstrated that these elevations are endogenous responses addressed to limit brain damage, as the inhibition of 2-AG and anandamide hydrolysis reduced brain damage and improved functional deficits in parallel to a reduction of proinflammatory responses in the mouse brain after TBI [45, 46]. Similar elevations of anandamide, $2-\mathrm{AG}$, and $\mathrm{N}$ acylethanolamines have been detected in experimental cerebral ischemia [47-50]. As far as the cannabinoid receptors are concerned, most studies showed an upregulated expression of both $\mathrm{CB}_{1} \mathrm{R}$ and, in particular, $\mathrm{CB}_{2} \mathrm{R}$ in stroke, with neurons (for $\mathrm{CB}_{1} \mathrm{R}$ ) and microglial/macrophages, astrocytes, and neutrophils (for $\mathrm{CB}_{2} \mathrm{R}$ ) being the most common cellular substrates for these responses [33, 51-54]. However, some studies described downregulatory responses of both receptors at very early times after induction of ischemia $[33,55]$. Upregulation of $\mathrm{CB}_{2} \mathrm{R}$ with no changes in $\mathrm{CB}_{1} \mathrm{R}$ have been found in $\mathrm{TBI}$ [56].

Despite the elevated number of preclinical studies, the number of clinical studies with cannabinoids in these pathological conditions is rather limited. The most relevant was a multicenter, placebo-controlled, phase III trial conducted 10 years ago, and that was addressed to determine safety and efficacy of dexanabinol in patients with TBI. The trial did show that dexanabinol was safe but not efficacious for the treatment of TBI [57]. It is important to remark that dexanabinol is a cannabinoid because of its chemical structure (it is the inactive enantiomer of HU-210) but it does not have any activity at the classic cannabinoid receptors, being active as a noncompetitive NMDA receptor antagonist, so there is an unmet need of repeating such clinical studies with compounds acting at $\mathrm{CB}_{1} \mathrm{R}$ and/or $\mathrm{CB}_{2} \mathrm{R}$ (e.g., Sativex; GWPharma, Cambridge, UK).

\section{Cannabinoids and Brain Damage in the Immature Brain: Neonatal Hypoxia-Ischemia}

Perinatal asphyxia affects 1-2 per 1000 live term newborns with one-third of them developing a severe neurological syndrome. About $25 \%$ of severe cases result in lasting sequelae and about $20 \%$ die, resulting in about 2 million babies dying or remaining severely disabled each year worldwide [58]. Immature brain show some characteristics that determine a higher vulnerability for hypoxic-ischemic (HI) damage, as well as some particular selectivity for the damage [58-61]: 1) a high metabolic rate and oxygen extraction together with immature glucose uptake mechanisms; 2) a highly developed excitotoxic system which overexpressed receptors responding faster and higher to glutamate; 3) hypersensitivity to inflammatory mediators, with a misbalance between pro- and antioxidant enzymes, differences in leukocyte-endothelial cell communication and distinct intracellular signaling within inflammatory pathways (NFKB and mitogen-activated protein kinase); 4) proapoptotic factor preponderancy because of the need for modeling the developing brain; and 5) antioxidant defenses only partially developed at birth. Therefore, excitotoxicity, inflammation, and oxidative stress 
constitute the triad of major factors leading to HI damage in immature brain [59]. However, immature brain has a huge plastic recovery potential after ischemia, increasing the proliferation in the subventricular zone of neural precursors that then migrate to the damaged areas in the neocortex [61], as well as of glial precursors that migrate similarly to support the newly created neurons [60]. The high vulnerability to oxidative stress of particularly active oligodendroglial cells because of the ongoing myelinization processes with enhanced iron metabolism, however, jeopardizes this process [61]. Thus, despite the fact that oligodendroglial precursors accumulate in brain after $\mathrm{HI}$ the absence of further progress to mature forms eventually results in hypomyelination [62]. In addition, despite the greater resistance of the BBB to the ischemic insult in newborn than in adult brain, the angiogenic response in immature brain is slower and weaker than in adults, which can compromise the postischemic neurorepair [63]. The existence of a lapse between primary and secondary energetic failure on brain after a $\mathrm{HI}$ insult offers an opportunity for treatment, a "therapeutic window". However, currently available therapies for ischemic brain damage only afford partial protection. An example is therapeutic hypothermia for asphyxiated newborns. Although current evidence demonstrates that hypothermia reduces death and/or major sequelae, almost a half of babies with severe HI encephalopathy do not benefit from this treatment; in addition, its application in substandard environments might be troublesome or even dangerous [64]. Thus, to develop synergistic therapies is warranted.

Given that cannabinoids are able to attenuate excitotoxicity, inflammation, and oxidative stress, they have been proposed as promising candidates to become effective neuroprotective therapies, including the brain damage in neonatal ischemia [63]. This evidence derives from studies that were initiated $>10$ years ago using newborn rat forebrain slices subjected to oxygen glucose deprivation and exposed to the $\mathrm{CB}_{1} \mathrm{R} / \mathrm{CB}_{2} \mathrm{R}$ agonist WIN55212-2, which reduced cell death, decreasing glutamate and cytokine release, as well as inducible nitric oxide synthase expression, effects that were abolished by either $\mathrm{CB}_{1} \mathrm{R}$ or $\mathrm{CB}_{2} \mathrm{R}$ antagonists [65]. In newborn rats exposed to severe anoxia or to acute hypoxiaischemia [66, 67], postinsult administration of WIN55212-2 afforded a strong neuroprotective effect, abolished by either $\mathrm{CB}_{1} \mathrm{R}$ or $\mathrm{CB}_{2} \mathrm{R}$ antagonists, too, as well as increasing neuronal and oligodendroglial cell proliferation in the subventricular zone 7 days after neonatal $\mathrm{HI}$ in rats [68]. In term fetal lambs exposed to HI damage by umbilical cord occlusion, postinsult administration of WIN55212-2 improved cerebral blood flow and reduced astrocytic, as well as apoptotic neuronal, death - those effects relying on the preservation of mitochondrial integrity and functionality [69]. These neuroprotective effects were also afforded with CBD, the major nonpsychoactive component of Cannabis sativa, again in animal models of newborn $\mathrm{HI}$ encephalopathy
[70-74]. CBD administered 15-30 min after an HI insult in newborn pigs reduced the death of neurons and astrocytes, preserved brain activity as measured by amplitude-integrated electroencephalography, prevented the increase in the concentration of $\mathrm{H}^{+}$magnetic resonance spectroscopy biomarkers of brain damage (e.g., lactate $/ N$-acetylaspartate ratio), prevented the appearance of seizures and improved neurobehavioral performance when examined $72 \mathrm{~h}$ after HI $[70,72,74]$. In the case of newborn rats, CBD administered 15 min after an HI insult led to long-lasting neuroprotective effects, reducing brain damage and restoring neurobehavioral function several weeks after the insult [73]. The neuroprotective effect of CBD included the prevention of necrotic and apoptotic cell death and was related to the modulation of excitotoxicity, inflammation, and oxidative stress, as demonstrated by in vitro and in vivo studies [71-74]. It is important to note that this neuroprotective action was associated with no significant side effects and even with some extracerebral benefits (e.g., improved hemodynamic stability and lung dynamics) [70, 72-74].

There are not too many data concerning the changes in endocannabinoid elements following a neonatal $\mathrm{HI}$ insult but the few available data support the findings derived from pharmacological studies. Thus, brain levels of endocannabinoids are increased in the newborn rat after acute injury and in the newborn pig after acute brain $\mathrm{HI}$ insult $[74,75]$, which has been interpreted as a part of an endogenous response of the endocannabinoid signaling system acting as a natural neuroprotective system.

Therefore, the preclinical evidence collected so far is highly suggestive of important benefits to be reached in newborns affected by $\mathrm{HI}$ encephalopathy with cannabinoid-based therapies, in particular with the nonpsychoactive phytocannabinoid $\mathrm{CBD}$, which appears to be an adequate therapeutic option for the treatment of neonatal and infantile disorders. In fact, CBD has already been formulated as Epidiolex (GWPharma) and received the orphan designation from US and European regulatory agencies for the treatment infantile refractory epilepsies [76]. It may be a good choice for investigating the benefits of cannabinoid-based therapies in neonatal ischemia at the clinical level, alone or in combination with hypothermia, which is the only approved therapeutic strategy for this pathological condition.

\section{Cannabinoids and Chronic Neurodegenerative Disorders: I. AD}

$\mathrm{AD}$ represents the most prevalent chronic progressive neurodegenerative disorder. It may have a genetic origin with 3 major causal genes (APP, PSEN1, PSEN2) and numerous risk genes (APOE, SORL1, CLU, and others) but they account only $<20 \%$ of cases, most of them being of sporadic origin 
[77]. AD is characterized by a progressive cognitive deterioration leading to dementia, which affects mainly cortical and subcortical structures [78]. The major histopathological events are: 1) the formation of extracellular accumulations of $\beta$ amyloid $(A \beta)$ protein called senile plaques; 2$)$ the development of cytoskeleton abnormalities, so-called neurofibrillary tangles, caused by hyperphosphorylation of tau protein; and 3) an important degree of the neuritic dystrophy and neuronal death in affected structures [79]. Therapies for AD are still limited, in particular for delaying disease progression with most of them still under investigation (e.g., inhibitors for acetylcholinesterase, NMDA receptors, $\beta$ - and $\gamma$-secretases, and tau protein hyperphosphorylation) [80], so there is an urgent need to discover novel targets and compounds.

Cannabinoids have also attracted interest in $\mathrm{AD}$ given their benefits in reducing classic neurotoxic events in the disease, such as excessive glutamatergic transmission, prolonged calcium influx, oxidative stress, and inflammation. They were successfully investigated in preclinical models (e.g., $5 \times \mathrm{FAD}, \mathrm{PS} 1 / \mathrm{APP}^{+}$mice) [81-85], despite it being well known that these models do not completely reproduce the complex AD pathology in humans, and this may be an important factor to consider at the time of developing and analyzing the results in future clinical trials. Beneficial effects in preclinical studies involved $\mathrm{CB}_{1} \mathrm{R}$ and/or $\mathrm{CB}_{2} \mathrm{R}$, the selective activation of which was found to be effective in improving cognitive impairment, preserving neuronal cells, and preventing $A \beta$-induced microglial activation and the generation of proinflammatory mediators, as well as removing pathological deposits in different in vivo and in vitro models of AD [86-90]. In addition, beneficial effects of cannabinoids in AD may also be, at least partially, related to the activation of PPAR nuclear receptors for which certain cannabinoids may serve as ligands [88,91], whereas, in the case of some particular cannabinoids (e.g., antioxidant phytocannabinoids), they may exert some more specific effects in relation with $\mathrm{AD}$ pathogenesis, for example: 1) by preventing $A \beta$ aggregation, thereby hindering plaque formation and reducing the density of neuritic plaques due to inhibition of acetylcholinesterase activity or increased expression of neprilysin, an enzyme in the $A \beta$ degradation cascade $[86,91-94]$; and 2 ) by inhibiting $\mathrm{A} \beta$-induced tau protein hyperphosphorylation by glycogen synthase kinase- $3 \beta$ [82-84]. Some recent studies have also highlighted the interest of targeting endocannabinoid inactivation in $\mathrm{AD}$, through strategies of genetic inactivation [e.g., mice deficient in monoacylglycerol lipase (MAGL) or fatty acid amide hydrolase (FAAH)] or by inhibiting these enzymes (e.g., JZL184, URB597, respectively) [95-98]. However, in some cases, these effects were not related to an increased $\mathrm{CB}_{1} \mathrm{R}$ and/or $\mathrm{CB}_{2} \mathrm{R}$ signaling, but to other pathways, for example PPAR signaling, alterations in arachidonic acid, and/or prostaglandin signaling $[95,96]$.
The neuroprotective effects of cannabinoids may be likely facilitated by the changes experienced by specific elements of the endocannabinoid signaling system during the progression of $\mathrm{AD}$. This is the case, for example, of the upregulation of $\mathrm{CB}_{2} \mathrm{R}$ found in reactive microglial cells surrounding the $\mathrm{A} \beta$ plaques, a response found in postmortem brain tissues from patients with $\mathrm{AD}[87,99]$, and also in some experimental models [87], which may facilitate the benefits found with compounds selectively targeting this receptor $[86,87,90]$. However, other effects are better explained as originated by a pharmacological correction of those changes in the endocannabinoid system that may contribute to the progression of $\mathrm{AD}$ pathogenesis, for example: 1) the reduction in $\mathrm{CB}_{1} \mathrm{R}$ observed in $\mathrm{AD}$-affected areas [87, 100], which may aggravate excitotoxic events that are controlled by $\mathrm{CB}_{1} \mathrm{R}$ signaling, then enhancing neuronal losses; and 2) the elevation of the FAAH enzyme in astrocytes associated with the senile plaques in the postmortem human cortex, which would enhance endocannabinoid hydrolysis, then decreasing anandamide levels and elevating arachidonic acid levels, and contributing to the destructive inflammatory process that accompanies AD $[99,101]$, despite studies in $\mathrm{PS} 1 / \mathrm{APP}^{+}$mice describing an increase in brain levels of monoacylglycerols, $\mathrm{N}$ acylethanolamines, free fatty acids, eicosanoids, and other lipid species [96].

Despite the positive results obtained with cannabinoids in preclinical models of $\mathrm{AD}$, their clinical development for patients with $\mathrm{AD}$ is still very poor, and it will be a complicated task given that these preclinical models only partially reproduce the disease, as mentioned before. The few clinical studies conducted so far have concentrated on specific symptoms, for example dementia-induced loss of appetite [102], but they have not investigated any disease-modifying effect. An interesting formulation to be investigated at the clinical level is the recently licensed phytocannabinoid-based medicine Sativex (GWPharma), which, based on the activity of its 2 components, $\Delta^{9}$-THC and CBD, at different complementary targets identified as neuroprotective in $\mathrm{AD}$, e.g. $\mathrm{CB}_{1} \mathrm{R}$ and $\mathrm{CB}_{2} \mathrm{R}$, PPARs, could become a promising novel disease-modifying therapy for patients with $\mathrm{AD}$, as has been recently demonstrated in a preclinical model of an AD-related disorder (frontotemporal dementia) [103].

\section{Cannabinoids and Chronic Neurodegenerative Disorders: II. PD}

The most important progressive neurodegenerative disorder affecting the basal ganglia is PD. With an incidence of 2 cases per 10,000 people, PD is caused preferentially by overexposure to different environmental factors (e.g., pesticides, insecticides, some medicines, metals) but also ( $<5 \%$ of cases) by mutations in some genes encoding for proteins such as $\alpha$ - 
synuclein, parkin, PINK1 (phosphatase and tensin homologinduced putative kinase 1) and LRRK2 (leucine-rich repeat kinase 2) [104]. PD affects numerous brain structures, then producing different nonmotor (e.g., drooling, changes in taste and smell, nausea and vomiting, constipation, bladder dysfunction, dementia and cognitive impairment, hallucinations, depression and anxiety, and others) and, in particular, motor (e.g., rigidity, bradykinesia, postural instability, tremor) anomalies [105]. Motor symptoms are predominantly caused by alterations in the basal ganglia circuitry triggered by the death of nigral dopaminergic neurons, the denervation of the striatum to which these degenerating neurons project, the formation of Lewy bodies in the cytosol of nigral neurons, and the loss of neuromelanin accumulated in the substantia nigra [106]. Current treatments include dopaminergic replacement therapies, which serve for symptom alleviation, but the disease lacks of efficacious disease-modifying therapies, despite the issue being widely investigated, even at the clinical level [107].

As in the case of $\mathrm{AD}$, numerous cannabinoids have been investigated with the objective of developing novel neuroprotective therapies in experimental models of $\mathrm{PD}$, for example 6-hydroxydopamine-lesioned rodents, 1-methyl-4phenyl-1,2,3,6-tetrahydropyridine (MPTP)- or lipopolysaccharide (LPS)-lesioned mice [108], despite these neurotoxin-based models reflecting only partial aspects of the complex PD pathology, with some important events (e.g., Lewy body formation) completely absent. These studies have concentrated on the antioxidant properties of phytocannabinoids, for example $\Delta^{9}$-THC [109], CBD [109-111], and $\Delta^{9}$-tetrahydrocannabivarin $\left(\Delta^{9}\right.$-THCV) [111], which are cannabinoid receptor-independent, then reducing oxidative stress, which is a major hallmark in the pathogenesis of PD that may be experimentally reproduced in laboratory animals. Neuroprotection has also been provided by synthetic cannabinoids such as the endocannabinoid transporter inhibitor/vanilloid agonist AM404 [110], or the $\mathrm{CB}_{1} \mathrm{R} / \mathrm{CB}_{2} \mathrm{R}$ agonist $\mathrm{CP} 55,940$ [112], which are also antioxidant and also work through cannabinoid receptor-independent mechanisms in this case. In contrast, cannabinoids that selectively target the $\mathrm{CB}_{2} \mathrm{R}$ were also active against local inflammation and gliosis in models of mitochondrial dysfunction or LPS insult [111, 113, 114], a fact also supported by studies conducted with classic parkinsonian neurotoxins administered to mice with genetic deletion of the $\mathrm{CB}_{2} \mathrm{R}$ (greater vulnerability against the insult) or overexpressing these receptors (lower susceptibility against the insult) [111, 115]. $\mathrm{CB}_{1} \mathrm{R}$-activating compounds have also been studied, but with controversial results $[110,116]$. Nevertheless, a neuroprotective strategy based on targeting $\mathrm{CB}_{1} \mathrm{R}$ might have some disadvantages in PD as the hypokinetic effects of $\mathrm{CB}_{1} \mathrm{R}$ may worsen bradykinesia and other parkinsonian symptoms [108], whereas the blockade of these receptors may reduce parkinsonian akinesia [117].
Again, these pharmacological effects may be influenced by the changes that the endocannabinoid system experienced in this disease, as revealed by the data collected in postmortem tissues and biological fluids $[114,118,119]$, as well as those found in animal models $[111,113,118,120]$. They include: 1) the upregulation of $\mathrm{CB}_{1} \mathrm{R}$ in striatal neurons under the control of dopaminergic neurons that degenerate in $\mathrm{PD}$, as observed in postmortem tissue from patients and in different experimental models of the disease (reviewed in [108]); 1) the elevation of $\mathrm{CB}_{2} \mathrm{R}$ in glia recruited to the lesion sites in the postmortem substantia nigra of patients with $\mathrm{PD}$ and in mice lesioned with MPTP or LPS [111, 113, 114]; and 3) the loss of neuronal $\mathrm{CB}_{2} \mathrm{R}$ in postmortem tissues of patients with $\mathrm{PD}$ due to the degeneration of nigrostriatal dopaminergic neurons [121, 122].

Lastly, clinical studies with cannabinoids in patients with PD are still limited, with most of them addressing only the relief of specific symptoms, for example bradykinesia [123], tremor [124], and levodopa-induced dyskinesia [125]. No clinical data exist in relation to the neuroprotective effects of cannabinoids. However, the preclinical evidence collected so far supports that an effective therapy should be based on an adequate combination of compounds to ensure: 1) the antioxidant activity that would be exerted by cannabinoid receptorindependent mechanisms, possibly involving the activation of PPARs; 2) the control of inflammatory events by $\mathrm{CB}_{2} \mathrm{R}$ activation; and 3) the blockade of $\mathrm{CB}_{1} \mathrm{R}$ to reduce motor inhibition. The phytocannabinoid $\Delta^{9}$-THCV has such a profile, making it an interesting compound to be used therapeutically in $\mathrm{PD}$, alone or in combination with $\mathrm{CBD}$, and highlighting the need for a formulation that can be further evaluated in patients.

\section{Cannabinoids and Chronic Neurodegenerative Disorders: III. HD}

HD is a genetic disorder caused by an excessive number of CAG repeats in the gene encoding the regulatory protein huntingtin, being the most prevalent polyglutamine disorder, which also includes other diseases such as autosomal dominant hereditary ataxias [126]. The key symptoms in HD are choreic movements, which are produced by the degeneration of the striatum, and behavioral disturbances and dementia, which are caused by deterioration in cortical structures [127], whereas the key neuropathological features are the formation of intranuclear inclusions of the mutated huntingtin, ubiquitin, and other molecules, which have a critical influence in producing transcriptional dysregulation affecting a number of key genes (e.g., $B D N F$ ) and the death of a number of extremely vulnerable neuronal subpopulations (e.g., striatal projecting neurons) [128]. Pharmacological therapies for patients with HD are extremely limited, with only the inhibitor 
of the vesicular monoamine transporter 1 tetrabenazine (Xenazine; Lundbeck, Deerfield, IL, USA) approved for the treatment of choreic movements, but with poor results in most of patients [129]. There are no approved disease modifiers, although numerous antioxidants, minocycline, histone deacetylase inhibitors, and unsaturated fatty acids have been (or are being presently) investigated at the clinical level [129].

Cannabinoids in the form of Sativex (GWPharma) have been recently evaluated in patients with HD [130]. This was supported by an exhaustive preclinical work with positive results in a broad spectrum of animal models of HD (e.g., R6/2 mice, quinolinate-lesioned mice, 3-nitropropionate- or malonate-lesioned rats), which confirmed the benefits of cannabinoids against most of the cytotoxic stimuli acting in this disease (reviewed in $[1,2,131]$ ). For example, compounds targeting the $\mathrm{CB}_{1} \mathrm{R}$ preserved striatal neurons in studies conducted in a rat model that relies on quinolinate-induced excitotoxic damage [132]. The relevance of these receptors in HD was also demonstrated in a genetic model of the disease, $\mathrm{R} 6 / 2$ mice, in which $\mathrm{CB}_{1} \mathrm{R}$ activation again preserved striatal neurons from death, whereas striatal damage was aggravated in R6/2 mice having a genetic deficiency in $\mathrm{CB}_{1} \mathrm{R}$ [133]. Compounds that selectively activate the $\mathrm{CB}_{2} \mathrm{R}$ also appear to be effective in HD, preferentially ameliorating the inflammatory events and microglial activation that occurs after the striatum is damaged with malonate (a complex II inhibitor) in rats [134], in R6/2 mice [135], and following the excitotoxicity induced by striatal lesion with quinolinate in mice [136]. Antioxidant nonpsychoactive phytocannabinoids, such as CBD and cannabigerol (CBG), have also been investigated in experimental models of $\mathrm{HD}$, even though its effects are independent of $\mathrm{CB}_{1} \mathrm{R} / \mathrm{CB}_{2} \mathrm{R}$. Their effects may be mediated by activation of PPARs or other nonendocannabinoid targets. CBD was very active in animal models characterized by mitochondrial damage, oxidative stress and calpain activation, such as rats intoxicated with the complex II inhibitor 3nitropropionate [136], yet it was inactive in proinflammatory models like malonate-lesioned rats [134]. CBG was neuroprotective in 3-nitropropionate-lesioned and R6/2 mice [137]. Based on these beneficial effects, CBD combined with $\Delta^{9}$ $\mathrm{THC}$, as in the cannabinoid-based medicine Sativex (GWPharma), has also been studied in animal models of HD given the wide spectrum of pharmacological actions produced by this combination. This combination preserved striatal neurons in malonate-lesioned mice and in 3-nitropropionatelesioned rats $[138,139]$.

An important observation in relation to the changes experienced by the endocannabinoid signaling during the progression of $\mathrm{HD}$ is that early defects in $\mathrm{CB}_{1} \mathrm{R}$ signaling followed by a progressive loss of these receptors have been found even prior to neuronal death and the onset of choreic symptoms $[140,141]$. This may explain why an early stimulation of these receptors may dampen their impairment, thereby maintaining their capacity to inhibit the excitotoxic events that initiate the damage to striatal neurons [132], although such an approach is unlikely to work at later symptomatic stages that are characterized by an important loss of $\mathrm{CB}_{1} \mathrm{R}$-containing striatal neurons [117]. However, as recent study unequivocally demonstrated that $\mathrm{CB}_{1} \mathrm{R}$-dependent neuroprotective activity in $\mathrm{HD}$ is predominantly derived from a restricted population of these receptors on cortical glutamatergic neurons that project to the striatum and that are preserved during the progression of $\mathrm{HD}$ rather than from the $\mathrm{CB}_{1} \mathrm{R}$ located on striatal projection $\gamma$ aminobutyric acid (GABA)-ergic neurons that are progressively lost during disease progression [142], supporting the relevance of these receptors as potential targets for a neuroprotective therapy with cannabinoids in HD. In addition, the benefits found after $\mathrm{CB}_{2} \mathrm{R}$ activation in $\mathrm{HD}$ may be facilitated by overexpression of these receptors in the striatal parenchyma, an effect that was first detected when striatal damage was provoked in rats with malonate [134], and in R6/2 mice and other genetic mouse models of HD [135, 143], as well as in postmortem tissues from patients with HD [134]. This upregulation appears to occur in astrocytes [134] (although no $\mathrm{CB}_{2} \mathrm{R}$ expression was found in these glial cells in human HD tissues [144]) and particularly in reactive microglia [134, 135].

Cannabinoids have been also examined in patients with $\mathrm{HD}$, although these clinical trials concentrated on the alleviation of specific symptoms, particularly chorea and behavioral disturbances, with controversial results (reviewed in [1]). The only clinical trial aimed at validating a cannabinoid-based neuroprotective therapy in HD has been recently carried out in Spain using Sativex (GWPharma), and, although it successfully demonstrated that Sativex (GWPharma) was safe and well-tolerated in patients with $\mathrm{HD}$, as previously found in controls, yet, unfortunately, it failed to provide any evidence that it may slow down disease progression in HD [130]. This may be related to the relatively short time (12 weeks) for the active treatment and an unexpected influence of the placebo effect, so it is possible that a longer time may be necessary for revealing neuroprotective effects in patients with HD treated with Sativex (GWPharma) or similar preparations.

\section{Cannabinoids and Chronic Neurodegenerative Disorders: IV. ALS}

ALS is a progressive neurodegenerative disease produced by the damage of the upper and lower motor neurons leading to muscle denervation, atrophy, and paralysis [145]. As in other disorders, the damage of these neurons occurs by the combination of excitotoxicity, chronic inflammation, oxidative stress, protein aggregation, and other cytotoxic events [146-148]. The most abundant cases of ALS are sporadic [149], but the disease may be also familiar, associated with mutations in genes encoding for superoxide dismutase-1 
(SOD-1), TAR-DNA binding protein-43 (TDP-43) or FUS (fused in sarcoma) protein, as well as the more recent CCGGGG hexanucleotide expansion in C9orf72 [145, 148]. In familiar cases, which account for only $5 \%$ of all ALS cases, depending on the mutated gene (e.g., TDP-43, FUS, C9orf72), ALS can be accompanied by features of frontotemporal lobar dementia, which supports the idea that, rather than being one disorder, ALS belongs to a spectrum of disorders having motor and cognitive deficits [150]. The disease still lacks an effective treatment for symptoms and/or disease progression, with the antiexcitotoxic agent riluzole (Rilutek, Sanofi Pharmaceuticals, Paris, France) as the only approved medicine [151].

Studies initiated in 2004 have situated cannabinoids as a possible and promising disease-modifying therapy in ALS $[152,153]$, based on solid evidence collected exclusively in the classic transgenic mouse that overexpresses a mutated form (G93A) of SOD-1, despite this model only representing a small percentage of ALS cases. The model was developed in the 1990s and was used to investigate the effects of $\Delta^{9}$-THC [154], cannabinol [155], WIN55,212-2 [156], and the selective $\mathrm{CB}_{2} \mathrm{R}$ agonist AM1241 $[157,158]$. This solid pharmacological evidence is also supported by data collected from double mutants generated by crossing SOD-1 mutant mice with some of the different mice deficient in endocannabinoid genes (e.g., $F A A H^{-\alpha}, C B_{1}^{--}$), which not only reinforced the interest of $\mathrm{CB}_{1} \mathrm{R}$ agonists, but also the elevation of endocannabinoid levels with FAAH inhibitors [156]. Collectively, it appears that the neuroprotective effects of cannabinoids in ALS were apparently caused by 11) a $\mathrm{CB}_{2} \mathrm{R}$-mediated (and possibly involving PPAR- $\gamma$, too) reduction in microglial activation and neuroinflammation; 2) a $\mathrm{CB}_{1} \mathrm{R}$-mediated reduction in excitotoxic damage; and 3) antioxidant effects that appear to be receptor-independent and/or related to PPAR- $\gamma / \mathrm{Nrf}-2$ signaling [159].

As in other disorders, this efficacy of cannabinoid compounds in ALS may be determined by specific changes in endocannabinoid elements that are targeted by cannabinoids in the spinal cord, brainstem and cortical areas, the central nervous system structures more affected in this disease. Thus, the levels of anandamide and 2-AG are elevated in the spinal cord of SOD-1 mutant mice [156, 160], in parallel to an increase in the expression of N-acyl-phosphatidylethanolamine-selective phospholipase $\mathrm{D}$, the enzyme that synthesizes anandamide, but no changes in diacylglycerol lipase, the enzyme that synthesizes 2-AG, and in FAAH and MAGL, the 2 major degradative enzymes for the 2 major endocannabinoids [161]. In addition, $\mathrm{CB}_{2} \mathrm{R}$ experience an important upregulatory response in the spinal cord of SOD-1 mutant and TDP-43 transgenic mice [158, 161, 162], as well as in patients with ALS [163]. This upregulation appears to occur predominantly in microglial elements recruited at lesioned sites $[162,163]$, so that it may facilitate the beneficial effects derived from selectively targeting this receptor in the control of microglial toxicity for motor neurons. However, to determine the changes in $\mathrm{CB}_{1} \mathrm{R}$ remains controversial, with a study reporting downregulatory responses in the spinal cord of SOD-1 mutant mice, even at early presymptomatic phases [164], which may predispose motor neurons to excitotoxic events, given the role that $\mathrm{CB}_{1} \mathrm{R}$ play in the control of glutamate homeostasis. However, a further study conducted in the same mutant mice did not find any changes in $\mathrm{CB}_{1} \mathrm{R}$ in the spinal cord [161], and this has been recently confirmed in TDP-43 transgenic mice, too [162].

Cannabinoids have been also studied at the clinical level in ALS, although the number of clinical trials is still too small to get significant and reliable findings, thus stressing the urgent need for additional clinical investigation [152]. First studies were exclusively observational and based on patients with ALS who self-medicated with cannabis for attenuating specific ALS-related symptoms, for example cramps, spasticity, and drooling [165]. A randomized, double-blind crossover trial conducted with oral $\Delta^{9}$-THC studied its effects on cramps [166], which are an important symptom experienced by patients with ALS during the course of the disease. However, despite $\Delta^{9}$-THC being well-tolerated, there was no reduction in cramp frequency and intensity [166]. Two additional studies again indicated good tolerability of $\Delta^{9}$-THC in patients with ALS and a nonsignificant attenuation on cramps and fasciculations [167, 168]. There are no clinical studies so far that have tried to investigate the potential of cannabinoids as disease-modifying therapies, for example with the recently licensed cannabinoid-based medicine Sativex (GWPharma), which, given its broad-spectrum profile, may be adequate for clinical studies in patients with ALS following the results obtained in the preclinical studies (reviewed in [159]). In support of this possibility, we recently conducted a pharmacological study with a Sativex-like combination of phytocannabinoids in postsymptomatic SOD-1 mutant mice [161]. However, although the treatment preserved the motor neurons in the spinal cord, it did not completely preserve the neuron-muscle joint, producing a poor neurological recovery and no changes in animal survival [161], thus suggesting the need to use additional phytocannabinoid combinations for clinical studies.

\section{Concluding Remarks and Future Perspectives}

The studies reviewed here are all concordant with the view that cannabinoid-based medicines may serve as a novel therapy able to delay/arrest neurodegeneration in acute and chronic neurodegenerative conditions, owing to their capability of normalizing glutamate homeostasis, reducing oxidative injury, and/or attenuating local inflammatory events, and possibly also by their capability of activating cellular responses (e.g., 
induction of autophagy) in controlling the toxicity of protein aggregates, although this has not been addressed here. However, most of the studies that have examined the neuroprotective potential of these compounds in neurodegeneration have been conducted in animal or cellular models, whereas the few clinical trials that have investigated cannabinoid-based medicines were focused on the alleviation of specific symptoms and not on the control of disease progression. This latter aspect remains the major challenge for the future and it may be facilitated by the recent approval of the first cannabinoidbased medicines [e.g., Sativex (GWPharma), Epidiolex (GWPharma)] available for clinical use. These formulations, and additional combination of phytocannabinoids, present 2 important advantages: 2) its safety demonstrated in previous studies [169], despite the fact that manipulation of the endocannabinoid system may be harmful in certain circumstances [1], a fact deserving additional investigation; and 2) its broad-range profile that appears to be adequate for diseases in which different cytotoxic mechanisms cooperate to damage specific neuronal subpopulations. Therefore, it is expected and desirable that the issue recruits an important amount of clinical research in the future, which will allow for the promising expectation generated around the progress of these molecules from the present preclinical evidence to a real clinical exploitation.

\begin{abstract}
Acknowledgments This work was supported by grants from MINECO "Programa Nacional de Biomedicina" (SAF2012-39173; SAF201233216; CSD2010-00045); "Instituto de Salud Carlos III (ISCiii)", according to the "Plan Nacional de I+D+I 2008-2011"; and the "Plan Estatal de Investigación Científica y Técnica y de Innovación 20132016". Co-funding was from the European Regional Development Funds (FEDER) (FIS-PS09/01900, PS12/00192 and PI1301722); "Programa de Biomedicina de la Comunidad de Madrid" (S2010/BMD-2308, S2010/ BMD-2336); CIBERNED (CB06/05/0089); and GW Pharmaceuticals Ltd. We thank all colleagues that contributed to the studies conducted in the groups that have been mentioned here.
\end{abstract}

Required Author Forms Disclosure forms provided by the authors are available with the online version of this article.

\section{References}

1. Fernández-Ruiz J, Romero J, Ramos JA. Endocannabinoids and neurodegenerative disorders: Parkinson's disease, Huntington's chorea, Alzheimer's disease and others. In: Pertwee RG (ed.) Handbook of experimental pharmacology: endocannabinoids. Germany, Dortmund: Springer; 2015.

2. Fernández-Ruiz J, de Lago E, Gómez-Ruiz M, et al. Neurodegenerative disorders other than multiple sclerosis. In: Pertwee RG (ed.) Handbook of cannabis, Oxford University Press, Oxford, 2014, pp. 505-525.

3. Moskowitz MA, Lo EH, Iadecola C. The science of stroke: mechanisms in search of treatments. Neuron 2010;67:181-198.

4. Iadecola C, Anrather J. The immunology of stroke: from mechanisms to translation. Nat Med 2011;17:796-808.
5. Moretti A, Ferrari F, Villa RF. Neuroprotection for ischaemic stroke: current status and challenges. Pharmacol Ther 2015;146: 23-34.

6. Corps KN, Roth TL, McGavern DB. Inflammation and neuroprotection in traumatic brain injury. JAMA Neurol 2015;72:355-362.

7. England TJ, Hind WH, Rasid NA, O'Sullivan SE. Cannabinoids in experimental stroke: a systematic review and meta-analysis. J Cereb Blood Flow Metab 2015;35:348-358.

8. Belayev L, Busto R, Zhao W, Ginsberg MD. HU-211, a novel noncompetitive N-methyl-D-aspartate antagonist, improves neurological deficit and reduces infarct volume after reversible focal cerebral ischemia in the rat. Stroke 1995;26:2313-2319.

9. Shohami E, Novikov M, Bass R. Long-term effect of HU-211, a novel non-competitive NMDA antagonist, on motor and memory functions after closed head injury in the rat. Brain Res 1995;674: 55-62.

10. Shohami E, Gallily R, Mechoulam R, Bass R, Ben-Hur T. Cytokine production in the brain following closed head injury: dexanabinol (HU-211) is a novel TNF-alpha inhibitor and an effective neuroprotectant. J Neuroimmunol 1997;72:169-177.

11. Lavie G, Teichner A, Shohami E, Ovadia H, Leker RR. Long term cerebroprotective effects of dexanabinol in a model of focal cerebral ischemia. Brain Res 2001;901:195-201.

12. Leker RR, Gai N, Mechoulam R, Ovadia H. Drug-induced hypothermia reduces ischemic damage: effects of the cannabinoid HU210. Stroke 2003;34:2000-2006.

13. Nagayama T, Sinor AD, Simon RP, et al. Cannabinoids and neuroprotection in global and focal cerebral ischemia and in neuronal cultures. J Neurosci 1999;19:2987-2995.

14. Chi OZ, Barsoum S, Grayson J, et al. Effects of cannabinoid receptor agonist WIN 55,212-2 on blood-brain barrier disruption in focal cerebral ischemia in rats. Pharmacology 2012;89:333338.

15. Suzuki N, Suzuki M, Murakami K, et al. Cerebroprotective effects of TAK-937, a cannabinoid receptor agonist, on ischemic brain damage in middle cerebral artery occluded rats and non-human primates. Brain Res 2012;1430:93-100.

16. Murakami K, Suzuki M, Suzuki N, et al. Cerebroprotective effects of TAK-937, a novel cannabinoid receptor agonist, in permanent and thrombotic focal cerebral ischemia in rats: therapeutic time window, combination with t-PA and efficacy in aged rats. Brain Res 2013;1526:84-93.

17. Mauler F, Hinz V, Augstein KH, Fassbender M, Horváth E. Neuroprotective and brain edema-reducing efficacy of the novel cannabinoid receptor agonist BAY 38-7271. Brain Res 2003;989: 99-111.

18. Mauler F, Mittendorf J, Horváth E, De Vry J. Characterization of the diarylether sulfonylester (-)-(R)-3-(2-hydroxymethylindanyl4-oxy)phenyl-4,4,4-trifluoro-1-sulfonate (BAY 38-7271) as a potent cannabinoid receptor agonist with neuroprotective properties. J Pharmacol Exp Ther 2002;302:359-368.

19. Zani A, Braida D, Capurro V, Sala M. $\Delta$ 9-tetrahydrocannabinol (THC) and AM404 protect against cerebral ischaemia in gerbils through a mechanism involving cannabinoid and opioid receptors. Br J Pharmacol 2007;152:1301-1311.

20. Hayakawa K, Mishima K, Abe K, et al. Cannabidiol prevents infarction via the non-CB1 cannabinoid receptor mechanism. Neuroreport 2004;15:2381-2385.

21. Hayakawa K, Mishima K, Irie K, et al. Cannabidiol prevents a post-ischemic injury progressively induced by cerebral ischemia via a high-mobility group box 1-inhibiting mechanism. Neuropharmacology 2008;55:1280-1286.

22. Mishima K, Hayakawa K, Abe K, et al. Cannabidiol prevents cerebral infarction via a serotonergic 5-hydroxytryptamine1A receptor-dependent mechanism. Stroke 2005;36:1077-1082. 
23. Panikashvili D, Simeonidou C, Ben-Shabat S, et al. An endogenous cannabinoid (2-AG) is neuroprotective after brain injury. Nature 2001;413:527-531

24. Panikashvili D, Mechoulam R, Beni SM, Alexandrovich A, Shohami E. CB1 cannabinoid receptors are involved in neuroprotection via NF-kappa B inhibition. J Cereb Blood Flow Metab 2005;25:477-484.

25. Panikashvili D, Shein NA, Mechoulam R, et al. The endocannabinoid 2-AG protects the blood-brain barrier after closed head injury and inhibits mRNA expression of proinflammatory cytokines. Neurobiol Dis 2006;22:257-264.

26. Hillard CJ, Ho WS, Thompson J, et al. Inhibition of 2arachidonoylglycerol catabolism modulates vasoconstriction of rat middle cerebral artery by the thromboxane mimetic, U-46619. Br J Pharmacol 2007;152:691-698.

27. Hind WH, Tufarelli C, Neophytou M, et al. Endocannabinoids modulate human blood-brain barrier permeability in vitro. Br J Pharmacol 2015;172:3015-3027.

28. Schomacher M, Müller HD, Sommer C, Schwab S, Schäbitz WR. Endocannabinoids mediate neuroprotection after transient focal cerebral ischemia. Brain Res 2008;1240:213-220.

29. Cohen-Yeshurun A, Trembovler V, Alexandrovich A, et al. Narachidonoyl-L-serine is neuroprotective after traumatic brain injury by reducing apoptosis. J Cereb Blood Flow Metab 2011;31: 1768-1777.

30. Zhang M, Adler MW, Abood ME, et al. CB2 receptor activation attenuates microcirculatory dysfunction during cerebral ischemic/ reperfusion injury. Microvasc Res 2009;78:86-94.

31. Zhang M, Martin BR, Adler MW, et al. Modulation of cannabinoid receptor activation as a neuroprotective strategy for EAE and stroke. J Neuroimmune Pharmacol 2009;4:249-259.

32. Murikinati S, Jüttler E, Keinert T, et al. Activation of cannabinoid 2 receptors protects against cerebral ischemia by inhibiting neutrophil recruitment. FASEB J 2010;24:788-798.

33. Zarruk JG, Fernández-López D, García-Yébenes I, et al. Cannabinoid type 2 receptor activation downregulates strokeinduced classic and alternative brain macrophage/microglial activation concomitant to neuroprotection. Stroke 2012;43:211-219.

34. Amenta PS, Jallo JI, Tuma RF, Elliott MB. A cannabinoid type 2 receptor agonist attenuates blood-brain barrier damage and neurodegeneration in a murine model of traumatic brain injury. $\mathrm{J}$ Neurosci Res 2012;90:2293-2305.

35. Elliott MB, Tuma RF, Amenta PS, Barbe MF, Jallo JI. Acute effects of a selective cannabinoid-2 receptor agonist on neuroinflammation in a model of traumatic brain injury. J Neurotrauma 2011;28:973-981.

36. Garg P, Duncan RS, Kaja S, Koulen P. Intracellular mechanisms of $\mathrm{N}$-acylethanolamine-mediated neuroprotection in a rat model of stroke. Neuroscience 2010;166:252-262.

37. Parmentier-Batteur S, Jin K, Mao XO, Xie L, Greenberg DA. Increased severity of stroke in CB1 cannabinoid receptor knockout mice. J Neurosci 2002;22:9771-9775.

38. Bonfils PK, Reith J, Hasseldam H, Johansen FF. Estimation of the hypothermic component in neuroprotection provided by cannabinoids following cerebral ischemia. Neurochem Int 2006;49:508518.

39. Suzuki N, Suzuki M, Hamajo K, et al. Contribution of hypothermia and CB1 receptor activation to protective effects of TAK-937, a cannabinoid receptor agonist, in rat transient MCAO model. PLoS One 2012;7:e40889.

40. Aguado T, Romero E, Monory K, et al. The CB1 cannabinoid receptor mediates excitotoxicity-induced neural progenitor proliferation and neurogenesis. J Biol Chem 2007;282:23892-23898.

41. Cohen-Yeshurun A, Willner D, Trembovler V, et al. Narachidonoyl-L-serine (AraS) possesses proneurogenic properties in vitro and in vivo after traumatic brain injury. J Cereb Blood Flow Metab 2013;33:1242-1250.

42. Sun J, Fang Y, Chen T, et al. WIN55, 212-2 promotes differentiation of oligodendrocyte precursor cells and improve remyelination through regulation of the phosphorylation level of the ERK 1/2 via cannabinoid receptor 1 after stroke-induced demyelination. Brain Res 2013;1491:225-235.

43. Hansen HH, Ikonomidou C, Bittigau P, Hansen SH, Hansen HS. Accumulation of the anandamide precursor and other $\mathrm{N}$ acylethanolamine phospholipids in infant rat models of in vivo necrotic and apoptotic neuronal death. J Neurochem 2001;76:3946.

44. Hansen HH, Schmid PC, Bittigau P, et al. Anandamide, but not 2arachidonoylglycerol, accumulates during in vivo neurodegeneration. J Neurochem 2001;78:1415-1427.

45. Tchantchou F, Tucker LB, Fu AH, et al. The fatty acid amide hydrolase inhibitor PF-3845 promotes neuronal survival, attenuates inflammation and improves functional recovery in mice with traumatic brain injury. Neuropharmacology 2014;85:427-439.

46. Tchantchou F, Zhang Y. Selective inhibition of $\alpha / \beta$-hydrolase domain 6 attenuates neurodegeneration, alleviates blood brain barrier breakdown, and improves functional recovery in a mouse model of traumatic brain injury. J Neurotrauma 2013;30:565-579.

47. Berger C, Schmid PC, Schabitz WR, et al. Massive accumulation of $\mathrm{N}$-acylethanolamines after stroke. Cell signalling in acute cerebral ischemia? J Neurochem 2004;88:1159-1167.

48. Amantea D, Spagnuolo P, Bari M, et al. Modulation of the endocannabinoid system by focal brain ischemia in the rat is involved in neuroprotection afforded by $17 \beta$-estradiol. FEBS J 2007;274:4464-4475

49. Muthian S, Rademacher DJ, Roelke CT, Gross GJ, Hillard CJ Anandamide content is increased and CB1 cannabinoid receptor blockade is protective during transient, focal cerebral ischemia. Neuroscience 2004;129:743-750.

50. Degn M, Lambertsen KL, Petersen G, et al. Changes in brain levels of $\mathrm{N}$-acylethanolamines and 2-arachidonoylglycerol in focal cerebral ischemia in mice. J Neurochem 2007;103:1907-1916.

51. Ashton JC, Rahman RM, Nair SM, et al. Cerebral hypoxiaischemia and middle cerebral artery occlusion induce expression of the cannabinoid CB2 receptor in the brain. Neurosci Lett 2007;412:114-117.

52. Jin KL, Mao XO, Goldsmith PC, Greenberg DA. CB1 cannabinoid receptor induction in experimental stroke. Ann Neurol 2000;48:257-261.

53. Schmidt W, Schäfer F, Striggow V, Fröhlich K, Striggow F. Cannabinoid receptor subtypes 1 and 2 mediate long-lasting neuroprotection and improve motor behavior deficits after transient focal cerebral ischemia. Neuroscience 2012;227:313-326.

54. Vandeputte C, Casteels C, Struys T, et al. Small-animal PET imaging of the type 1 and type 2 cannabinoid receptors in a photothrombotic stroke model. Eur J Nucl Med Mol Imaging 2012;39:1796-1806.

55. Zhang M, Martin BR, Adler MW, et al. Modulation of the balance between cannabinoid $\mathrm{CB} 1$ and $\mathrm{CB} 2$ receptor activation during cerebral ischemic/reperfusion injury. Neuroscience 2008;152: 753-760.

56. Donat CK, Fischer F, Walter B, et al. Early increase of cannabinoid receptor density after experimental traumatic brain injury in the newborn piglet. Acta Neurobiol Exp (Wars) 2014;74:197-210.

57. Maas AI, Murray G, Henney H, 3rd, et al. Efficacy and safety of dexanabinol in severe traumatic brain injury: results of a phase III randomised, placebo-controlled, clinical trial. Lancet Neurol 2006;5:38-45.

58. Martinez-Orgado J, Fernández-Lopez D, Lizasoain I, Romero J. The seek of neuroprotection: introducing cannabinoids. Recent Patents CNS Drug Discov 2007;2:131-139. 
59. Johnston MV, Fatemi A, Wilson MA, Northington F. Treatment advances in neonatal neuroprotection and neurointensive care. Lancet Neurol 2011;10:372-382.

60. Villapol S, Gelot A, Renolleau S, Charriaut-Marlangue C. Astrocyte responses after neonatal ischemia: the yin and the yang. Neuroscientist 2008;14:339-344.

61. Volpe JJ. Hypoxic-ischemic encephalopathy: clinical aspects. In: Volpe JJ (ed.) Neurology of the newborn. Saunders-Elsevier, Philadelphia, PA, 2008, pp. 400-479.

62. Segovia KN, McClure M, Moravec M, et al. Arrested oligodendrocyte lineage maturation in chronic perinatal white matter injury. Ann Neurol 2008;63:520-530

63. Fernández-López D, Lizasoain I, Moro MA, Martínez-Orgado J. Cannabinoids: well-suited candidates for the treatment of perinatal brain injury. Brain Sci 2013;3:1043-1059.

64. Jacobs SE, Berg M, Hunt R, et al. Cooling for newborns with hypoxic ischaemic encephalopathy. Cochrane Database Syst Rev 2013;1:CD003311.

65. Fernández-Lopez D, Martínez-Orgado J, Núñez E, et al. Characterization of the neuroprotective effect of the cannabinoid agonist WIN-55212 in an in vitro model of hypoxic-ischemic brain damage in newborn rats. Pediatr Res 2006;60:169-173.

66. Martínez-Orgado J, Fernández-Frutos B, González R, et al. Neuroprotection by the cannabinoid agonist WIN-55212 in an in vivo newborn rat model of acute severe asphyxia. Mol Brain Res 2003;114:132-139.

67. Fernández-López D, Pazos MR, Tolón RM, et al. The cannabinoid agonist WIN55212 reduces brain damage in an in vivo model of hypoxic-ischemic encephalopathy in newborn rats. Pediatr Res 2007;62:255-260.

68. Fernández-López D, Pradillo JM, García-Yébenes I, et al. The cannabinoid WIN55212-2 promotes neural repair after neonatal hypoxia-ischemia. Stroke 2010;41:2956-2964.

69. Alonso-Alconada D, Alvarez A, Alvarez FJ, Martínez-Orgado JA, Hilario E. The cannabinoid WIN 55212-2 mitigates apoptosis and mitochondrial dysfunction after hypoxia ischemia. Neurochem Res 2012;37:161-170.

70. Alvarez FJ, Lafuente H, Rey-Santano MC, et al. Neuroprotective effects of the nonpsychoactive cannabinoid cannabidiol in hypoxic-ischemic newborn piglets. Pediatr Res 2008;64:653-658.

71. Castillo A, Tolón MR, Fernández-Ruiz J, Romero J, MartinezOrgado J. The neuroprotective effect of cannabidiol in an in vitro model of newborn hypoxic-ischemic brain damage in mice is mediated by CB2 and adenosine receptors. Neurobiol Dis 2010;37:434-440.

72. Lafuente H, Alvarez FJ, Pazos MR, et al. Cannabidiol reduces brain damage and improves functional recovery after acute hypoxia-ischemia in newborn pigs. Pediatr Res 2011;70:272-277.

73. Pazos MR, Cinquina V, Gómez A, et al. Cannabidiol administration after hypoxia-ischemia to newborn rats reduces long-term brain injury and restores neurobehavioral function. Neuropharmacology 2012;63:776-783.

74. Pazos MR, Mohammed N, Lafuente H, et al. Mechanisms of cannabidiol neuroprotection in hypoxic-ischemic newborn pigs: role of 5HT1A and $\mathrm{CB} 2$ receptors. Neuropharmacology 2013;71:282-291.

75. Mechoulam R, Lichtman AH. Stout guards of the central nervous system. Science 2003;302:65-67.

76. Devinsky O, Cilio MR, Cross H, et al. Cannabidiol: pharmacology and potential therapeutic role in epilepsy and other neuropsychiatric disorders. Epilepsia 2014;55:791-802.

77. Lewczuk P, Mroczko B, Fagan A, Kornhuber J. Biomarkers of Alzheimer's disease and mild cognitive impairment: a current perspective. Adv Med Sci 2015;60:76-82.
78. Braskie MN, Thompson PM. Understanding cognitive deficits in Alzheimer's disease based on neuroimaging findings. Trends Cogn Sci 2013;17:510-516.

79. Thal DR, Attems J, Ewers M. Spreading of amyloid, tau, and microvascular pathology in Alzheimer's disease: findings from neuropathological and neuroimaging studies. J Alzheimer Dis 2014;42:S421-S429.

80. Berk C, Paul G, Sabbagh M. Investigational drugs in Alzheimer's disease: current progress. Expert Opin Investig Drugs 2014;23: 837-846.

81. Karl T, Cheng D, Garner B, Arnold JC. The therapeutic potential of the endocannabinoid system for Alzheimer's disease. Expert Opin Ther Targets 2012;16:407-420.

82. Iuvone T, Esposito G, De Filippis D, Scuderi C, Steardo L. Cannabidiol: a promising drug for neurodegenerative disorders? CNS Neurosci Ther 2009; 15:65-75.

83. Esposito G, De Filippis D, Carnuccio R, Izzo AA, Iuvone T. The marijuana component cannabidiol inhibits $\beta$-amyloid-induced tau protein hyperphosphorylation through $\mathrm{Wnt} /$ beta-catenin pathway rescue in PC12 cells. J Mol Med 2006;84:253-258.

84. Esposito G, Scuderi C, Savani C, et al. Cannabidiol in vivo blunts $\beta$-amyloid induced neuroinflammation by suppressing IL-1 $\beta$ and iNOS expression. Br J Pharmacol 2007; 151:1272-1279.

85. Gowran A, Noonan J, Campbell VA. The multiplicity of action of cannabinoids: implications for treating neurodegeneration. CNS Neurosci Ther 2011;17:637-644.

86. Tolón RM, Núñez E, Pazos MR, et al. The activation of cannabinoid $\mathrm{CB} 2$ receptors stimulates in situ and in vitro $\beta$-amyloid removal by human macrophages. Brain Res 2009;1283:148-154.

87. Ramírez BG, Blázquez C, Gómez del Pulgar T, Guzmán M, de Ceballos ML. Prevention of Alzheimer's disease pathology by cannabinoids: neuroprotection mediated by blockade of microglial activation. J Neurosci 2005;25:1904-1913.

88. Fakhfouri G, Ahmadiani A, Rahimian R, et al. WIN55212-2 attenuates amyloid-beta-induced neuroinflammation in rats through activation of cannabinoid receptors and PPAR- $\gamma$ pathway. Neuropharmacology 2012;63:653-666.

89. Aso E, Palomer E, Juvés S, et al. CB1 agonist ACEA protects neurons and reduces the cognitive impairment of $\mathrm{A} \beta \mathrm{PP} / \mathrm{PS} 1$ mice. J Alzheimer Dis 2012;30:439-459.

90. Aso E, Juvés S, Maldonado R, Ferrer I. CB2 cannabinoid receptor agonist ameliorates Alzheimer-like phenotype in A $\beta P P / P S 1$ mice. J Alzheimer Dis 2013;35:847-858.

91. Scuderi C, Steardo L, Esposito G. Cannabidiol promotes amyloid precursor protein ubiquitination and reduction of $\beta$-amyloid expression in SHSY5YAPP+ cells through PPAR $\gamma$ involvement. Phytother Res 2014;28:1007-1013.

92. Martín-Moreno AM, Brera B, Spuch C, et al. Prolonged oral cannabinoid administration prevents neuroinflammation, lowers $\beta$ amyloid levels and improves cognitive performance in Tg APP 2576 mice. J Neuroinflammation 2012;9:8

93. Eubanks LM, Rogers CJ, Beuscher AE, et al. A molecular link between the active component of marijuana and Alzheimer's disease pathology. Mol Pharmacol 2006;3:773-777.

94. Chen R, Zhang J, Fan N, et al. $\Delta^{9}$-THC-caused synaptic and memory impairments are mediated through COX-2 signaling. Cell 2013;155:1154-1165.

95. Chen R, Zhang J, Wu Y, et al. Monoacylglycerol lipase is a therapeutic target for Alzheimer's disease. Cell Rep 2012;2:13291339.

96. Piro JR, Benjamin DI, Duerr JM, et al. A dysregulated endocannabinoid-eicosanoid network supports pathogenesis in a mouse model of Alzheimer's disease. Cell Rep 2012;1:617-623.

97. Benito C, Tolon RM, Castillo AI, et al. $\beta$-Amyloid exacerbates inflammation in astrocytes lacking fatty acid amide hydrolase through a mechanism involving PPAR $\alpha$, PPAR $\gamma$ and TRPV1, 
but not CB1 or CB2 receptors. Br J Pharmacol 2012;166:14741489.

98. Vázquez C, Tolón RM, Pazos MR, et al. Endocannabinoids regulate the activity of astrocytic hemichannels and the microglial response against an injury: In vivo studies. Neurobiol Dis 2015;79:41-50.

99. Benito C, Nuñez E, Tolon RM, et al. Cannabinoid CB2 receptors and fatty acid amide hydrolase are selectively overexpressed in neuritic plaque-associated glia in Alzheimer's disease brains. J Neurosci 2003;23:11136-11141.

100. Westlake TM, Howlett AC, Bonner TI, Matsuda LA, Herkenham M. Cannabinoid receptor binding and messenger RNA expression in human brain: an in vitro receptor autoradiography and in situ hybridization histochemistry study of normal aged and Alzheimer's brains. Neuroscience 1994;63:637-652.

101. Jung K, Astarita G, Yasar S, et al. An amyloid $\beta_{42}$-dependent deficit in anandamide mobilization is associated with cognitive dysfunction in Alzheimer's disease. Neurobiol Aging 2012;33: 1522-1532.

102. Volicer L, Stelly M, Morris J, McLaughlin J, Volicer BJ. Effects of dronabinol on anorexia and disturbed behavior in patients with Alzheimer's disease. Int J Geriatr Psychiatry 1997;12:913-919.

103. Casarejos MJ, Perucho J, Gómez A, et al. Natural cannabinoids improve dopamine neurotransmission and tau and amyloid pathology in a mouse model of tauopathy. J Alzheimer Dis 2013;35:525539 .

104. Reeve A, Simcox E, Turnbull D. Ageing and Parkinson's disease: why is advancing age the biggest risk factor? Ageing Res Rev 2014;14:19-30.

105. Lima MM, Martins EF, Delattre AM, et al. Motor and non-motor features of Parkinson's disease - a review of clinical and experimental studies. CNS Neurol Disord Drug Targets 2012;11:439449.

106. Dickson DW. Parkinson's disease and parkinsonism: neuropathology. Cold Spring Harb Perspect Med 2012;2:a009258.

107. Athauda D, Foltynie T. The ongoing pursuit of neuroprotective therapies in Parkinson's disease. Nat Rev Neurol 2015;11:25-40.

108. García-Arencibia M, García C, Fernández-Ruiz J. Cannabinoids and Parkinson's disease. CNS Neurol Disord Drug Targets 2009;8: 432-439.

109. Lastres-Becker I, Molina-Holgado F, Ramos JA, Mechoulam R, Fernández-Ruiz J. Cannabinoids provide neuroprotection against 6-hydroxydopamine toxicity in vivo and in vitro: relevance to Parkinson's disease. Neurobiol Dis 2005;19:96-107.

110. García-Arencibia M, González S, de Lago E, et al. Evaluation of the neuroprotective effect of cannabinoids in a rat model of Parkinson's disease: importance of antioxidant and cannabinoid receptor-independent properties. Brain Res 2007;1134:162-170.

111. García C, Palomo-Garo C, García-Arencibia M, et al. Symptomrelieving and neuroprotective effects of the phytocannabinoid $\Delta^{9}$ THCV in animal models of Parkinson's disease. Br J Pharmacol 2011;163:1495-1506.

112. Jiménez-Del-Rio M, Daza-Restrepo A, Velez-Pardo C. The cannabinoid CP55,940 prolongs survival and improves locomotor activity in Drosophila melanogaster against paraquat: implications in Parkinson's disease. Neurosci Res 2008;61:404-411.

113. Price DA, Martinez AA, Seillier A, et al. WIN55,212-2, a cannabinoid receptor agonist, protects against nigrostriatal cell loss in the 1-methyl-4-phenyl-1,2,3,6-tetrahydropyridine mouse model of Parkinson's disease. Eur J Neurosci 2009;29:2177-2186.

114. Gómez-Gálvez Y, Palomo-Garo C, Fernández-Ruiz J, García C. Potential of the cannabinoid CB2 receptor as a pharmacological target against inflammation in Parkinson's disease. Prog Neuropsychopharmacol Biol Psychiatry 2015 Apr 9 [Epub ahead of print].
115. Ternianov A, Pérez-Ortiz JM, Solesio ME, et al. Overexpression of $\mathrm{CB}_{2}$ cannabinoid receptors results in neuroprotection against behavioral and neurochemical alterations induced by intracaudate administration of 6-hydroxydopamine. Neurobiol Aging 2012;33: e1-e16.

116. Chung YC, Bok E, Huh SH, et al. Cannabinoid receptor type 1 protects nigrostriatal dopaminergic neurons against MPTP neurotoxicity by inhibiting microglial activation. J Immunol 2011;187: 6508-6517.

117. Fernández-Ruiz J. The endocannabinoid system as a target for the treatment of motor dysfunction. Br J Pharmacol 2009;156:10291040.

118. Lastres-Becker I, Cebeira M, de Ceballos M, et al. Increased cannabinoid $\mathrm{CB}_{1}$ receptor binding and activation of GTP-binding proteins in the basal ganglia of patients with Parkinson's disease and MPTP-treated marmosets. Eur J Neurosci 2001;14:18271832.

119. Pisani A, Fezza F, Galati S, et al. High endogenous cannabinoid levels in the cerebrospinal fluid of untreated Parkinson's disease patients. Ann Neurol 2005;57:777-779.

120. Gubellini P, Picconi B, Bari M, et al. Experimental parkinsonism alters endocannabinoid degradation: implications for striatal glutamatergic transmission. J Neurosci 2002;22:6900-6907.

121. García MC, Cinquina V, Palomo-Garo C, Rábano A, FernándezRuiz J. Identification of CB2 receptors in human nigral neurons that degenerate in Parkinson's disease. Neurosci Lett 2015;587:14

122. Sierra S, Luquin N, Rico AJ, et al. Detection of cannabinoid receptors $\mathrm{CB} 1$ and $\mathrm{CB} 2$ within basal ganglia output neurons in macaques: changes following experimental parkinsonism. Brain Struct Funct 2014 Jun 28 [Epub ahead of print].

123. Mesnage V, Houeto JL, Bonnet AM, et al. Neurokinin B, neurotensin, and cannabinoid receptor antagonists and Parkinson disease. Clin Neuropharmacol 2004;27:108-110.

124. Frankel JP, Hughes A, Lees AJ, Stern GM. Marijuana for parkinsonian tremor. J Neurol Neurosurg Psychiatry 1990;53:436.

125. Fox SH, Lang AE, Brotchie JM. Translation of nondopaminergic treatments for levodopa-induced dyskinesia from MPTP-lesioned nonhuman primates to phase IIa clinical studies: keys to success and roads to failure. Mov Disord 2006;21:1578-1594.

126. Zielonka D, Mielcarek M, Landwehrmeyer GB. Update on Huntington's disease: advances in care and emerging therapeutic options. Parkinsonism Relat Disord 2015;21:169-178.

127. Jankovic J, Roos RA. Chorea associated with Huntington's disease: to treat or not to treat? Mov Disord 2014;29:1414-1418.

128. Waldvogel HJ, Thu D, Hogg V, Tippett L, Faull RL. Selective neurodegeneration, neuropathology and symptom profiles in Huntington's disease. Adv Exp Med Biol 2012;769:141-152.

129. Sampaio C, Borowsky B, Reilmann R. Clinical trials in Huntington's disease: interventions in early clinical development and newer methodological approaches. Mov Disord 2014;29: 1419-1428.

130. García de Yébenes J. Neuroprotection by cannabinoids in Huntington's disease. Available at: https://clinicaltrials.gov/ct2/ show/NCT01502046?term $=$ NCT01502046\&rank $=1$. Accessed August 5, 2015.

131. Sagredo O, Pazos MR, Valdeolivas S, Fernandez-Ruiz J. Cannabinoids: novel medicines for the treatment of Huntington's disease. Recent Pat CNS Drug Discov 2012;7:4148.

132. Pintor A, Tebano MT, Martire A, et al. The cannabinoid receptor agonist WIN 55,212-2 attenuates the effects induced by quinolinic acid in the rat striatum. Neuropharmacology 2006;51:1004-1012.

133. Blázquez C, Chiarlone A, Sagredo O, et al. Loss of striatal type 1 cannabinoid receptors is a key pathogenic factor in Huntington's disease. Brain 2011;134:119-136. 
134. Sagredo O, González S, Aroyo I, et al. Cannabinoid CB2 receptor agonists protect the striatum against malonate toxicity: relevance for Huntington's disease. Glia 2009;57:1154-1167.

135. Palazuelos J, Aguado T, Pazos MR, et al. Microglial CB2 cannabinoid receptors are neuroprotective in Huntington's disease excitotoxicity. Brain 2009;132:3152-3164.

136. Sagredo O, Ramos JA, Decio A, Mechoulam R, Fernández-Ruiz J. Cannabidiol reduced the striatal atrophy caused 3-nitropropionic acid in vivo by mechanisms independent of the activation of cannabinoid, vanilloid TRPV1 and adenosine A2A receptors. Eur J Neurosci 2007;26:843-851.

137. Valdeolivas S, Navarrete C, Cantarero I, et al. Neuroprotective properties of cannabigerol in Huntington's disease: studies in R6/ 2 mice and 3-nitropropionate-lesioned mice. Neurotherapeutics 2015;12:185-199.

138. Valdeolivas S, Satta V, Pertwee RG, Fernández-Ruiz J, Sagredo O. Sativex-like combination of phytocannabinoids is neuroprotective in malonate-lesioned rats, an inflammatory model of Huntington's disease: role of $\mathrm{CB} 1$ and $\mathrm{CB} 2$ receptors. ACS Chem Neurosci 2012;3:400-406.

139. Sagredo O, Pazos MR, Satta V, et al. Neuroprotective effects of phytocannabinoid-based medicines in experimental models of Huntington's disease. J Neurosci Res 2011;89:1509-1518.

140. Glass M, Dragunow M, Faull RLM. The pattern of neurodegeneration in Huntington's disease: a comparative study of cannabinoid, dopamine, adenosine and GABA-A receptor alterations in the human basal ganglia in Huntington's disease. Neuroscience 2000;97:505-519.

141. Lastres-Becker I, Berrendero F, Lucas JJ, et al. Loss of mRNA levels, binding and activation of GTP-binding proteins for cannabinoid CB1 receptors in the basal ganglia of a transgenic model of Huntington's disease. Brain Res 2002;929:236-242.

142. Chiarlone A, Bellocchio L, Blázquez C, et al. A restricted population of CB1 cannabinoid receptors with neuroprotective activity. Proc Natl Acad Sci USA 2014;111:8257-8262.

143. Bouchard J, Truong J, Bouchard K, et al. Cannabinoid receptor 2 signaling in peripheral immune cells modulates disease onset and severity in mouse models of Huntington's disease. J Neurosci 2012;32:18259-18268.

144. Dowie MJ, Grimsey NL, Hoffman T, Faull RL, Glass M. Cannabinoid receptor CB2 is expressed on vascular cells, but not astroglial cells in the post-mortem human Huntington's disease brain. J Chem Neuroanat 2014;59-60:62-71.

145. Hardiman O, van den Berg LH, Kiernan MC. Clinical diagnosis and management of amyotrophic lateral sclerosis. Nat Rev Neurol 2011;7:639-649.

146. Foran E, Trotti D. Glutamate transporters and the excitotoxic path to motor neuron degeneration in amyotrophic lateral sclerosis. Antioxid Redox Signal 2009;11:1587-1602.

147. Ferraiuolo L, Kirby J, Grierson AJ, Sendtner M, Shaw PJ. Molecular pathways of motor neuron injury in amyotrophic lateral sclerosis. Nat Rev Neurol 2011;7:616-630.

148. Renton AE, Majounie E, Waite A, et al. A hexanucleotide repeat expansion in C9ORF72 is the cause of chromosome 9p21-linked ALS-FTD. Neuron 2011;72:257-268.

149. Al-Chalabi A, Hardiman O. The epidemiology of ALS: a conspiracy of genes, environment and time. Nat Rev Neurol 2013;9:617-628.

150. Cruts M, Gijselinck I, Van Langenhove T, van der Zee J, Van Broeckhoven C. Current insights into the C9orf72 repeat expansion diseases of the FTLD/ALS spectrum. Trends Neurosci 2013;36:450-459.

151. Habib AA, Mitsumoto H. Emerging drugs for amyotrophic lateral sclerosis. Expert Opin Emerg Drugs 2011;16:537-558.

152. Carter GT, Abood ME, Aggarwal SK, Weiss MD. Cannabis and amyotrophic lateral sclerosis: hypothetical and practical applications, and a call for clinical trials. Am J Hosp Palliat Care 2010;27:347-356.

153. Rossi S, Bernardi G, Centonze D. The endocannabinoid system in the inflammatory and neurodegenerative processes of multiple sclerosis and of amyotrophic lateral sclerosis. Exp Neurol 2010;224:92-102.

154. Raman C, McAllister SD, Rizvi G, et al. Amyotrophic lateral sclerosis: delayed disease progression in mice by treatment with a cannabinoid. Amyotroph Lateral Scler Other Motor Neuron Disord 2004;5:33-39.

155. Weydt $\mathrm{P}$, Hong $\mathrm{S}$, Witting A, et al. Cannabinol delays symptom onset in SOD1 (G93A) transgenic mice without affecting survival. Amyotroph Lateral Scler Other Motor Neuron Disord 2005;6:182184.

156. Bilsland LG, Dick JR, Pryce G, et al.. Increasing cannabinoid levels by pharmacological and genetic manipulation delay disease progression in SOD1 mice. FASEB J 2006;20:1003-1005.

157. Kim K, Moore DH, Makriyannis A, Abood ME. AM1241, a cannabinoid CB2 receptor selective compound, delays disease progression in a mouse model of amyotrophic lateral sclerosis. Eur J Pharmacol 2006;542:100-105.

158. Shoemaker JL, Seely KA, Reed RL, Crow JP, Prather PL. The CB2 cannabinoid agonist AM-1241 prolongs survival in a transgenic mouse model of amyotrophic lateral sclerosis when initiated at symptom onset. J Neurochem 2007;101:87-98.

159. de Lago E, Moreno-Martet M, Espejo-Porras F, Fernández-Ruiz J. Endocannabinoids and amyotrophic lateral sclerosis. In: Fattore L (ed.) Cannabinoids in neurologic and mental disease. Elsevier, Amsterdam, 2015, pp. 99-124.

160. Witting A, Weydt P, Hong S, et al. Endocannabinoids accumulate in spinal cord of SOD1 G93A transgenic mice. J Neurochem 2004;89:1555-1557.

161. Moreno-Martet M, Espejo-Porras F, Fernández-Ruiz J, de Lago E. Changes in endocannabinoid receptors and enzymes in the spinal cord of SOD $1^{\mathrm{G} 93 \mathrm{~A}}$ transgenic mice and evaluation of a Sativex ${ }^{\circledR}$ like combination of phytocannabinoids: interest for future therapies in amyotrophic lateral sclerosis. CNS Neurosci Ther 2014;20: 809-815.

162. Espejo-Porras F, Piscitelli F, Verde R, et al. Changes in the endocannabinoid signaling system in CNS structures of TDP-43 transgenic mice: relevance for a neuroprotective therapy in TDP43-related disorders. J Neuroimmune Pharmacol 2015;10:233-244.

163. Yiangou Y, Facer P, Durrenberger P, et al. COX-2, CB2 and P2X7immunoreactivities are increased in activated microglial cells/ macrophages of multiple sclerosis and amyotrophic lateral sclerosis spinal cord. BMC Neurol 2006;6:12.

164. Zhao P, Ignacio S, Beattie EC, Abood ME. Altered presymptomatic AMPA and cannabinoid receptor trafficking in motor neurons of ALS model mice: implications for excitotoxicity. Eur J Neurosci 2008;27:572-579.

165. Amtmann D, Weydt P, Johnson KL, Jensen MP, Carter GT. Survey of cannabis use in patients with amyotrophic lateral sclerosis. Am J Hosp Palliat Care 2004;21:95-104.

166. Weber M, Goldman B, Truniger S. Tetrahydrocannabinol (THC) for cramps in amyotrophic lateral sclerosis: a randomised, doubleblind crossover trial. J Neurol Neurosurg Psychiatry 2010;81: $1135-1140$

167. Gelinas D, Miller R, Abood M. A pilot study of safety and tolerability of $\Delta^{9}$-THC (marinol) treatment for ALS. Amyotroph Lateral Scler Other Motor Neuron Disord 2002;3:23.

168. Joerger M, Wilkins J, Fagagnini S, et al. Single-dose pharmacokinetics and tolerability of oral $\Delta$ 9-tetrahydrocannabinol in patients with amyotrophic lateral sclerosis. Drug Metab Lett 2012;6:102-108.

169. Flachenecker P, Henze T, Zettl UK. Long-term effectiveness and safety of nabiximols (tetrahydrocannabinol/cannabidiol oromucosal spray) in clinical practice. Eur Neurol 2014;72:95-102. 